\title{
Lean-Burn Stationary Natural Gas Reciprocating Engine Operation with a Prototype Miniature Diode Side Pumped Passively Q-Switched Laser Spark Plug
}

\author{
Dustin L. McIntyre, Steven D. Woodruff, Michael H. McMillian, Steven W. Richardson \\ U.S. Department of Energy \\ National Energy Technology Laboratory \\ 3610 Collins Ferry Road \\ Morgantown WV, 26507
}

\author{
Mridul Gautam \\ West Virginia University \\ Department of Mechanical and Aerospace Engineering \\ Engineering Sciences Building \\ Morgantown, WV 26506
}

\begin{abstract}
To meet the ignition system needs of large bore lean burn stationary natural gas engines a laser diode side pumped passively Q-switched laser igniter was developed and used to ignite lean mixtures in a single cylinder research engine. The laser design was produced from previous work. The in-cylinder conditions and exhaust emissions produced by the miniaturized laser were compared to that produced by a laboratory scale commercial laser system used in prior engine testing. The miniaturized laser design as well as the combustion and emissions data for both laser systems was compared and discussed. It was determined that the two laser systems produced virtually identical combustion and emissions data.
\end{abstract}

\section{INTRODUCTION}

With increasing requirements being placed on reciprocating engine emissions and increasing demands for energy efficiency, the traditional spark ignition system is quickly reaching its practical durability limit, and its effectiveness in igniting ultra-lean fuel/air mixtures of natural gas. Laser ignition has the potential to advance large bore lean burn natural gas fueled engine technology by improving ignition system durability and ignitability and has shown the possibility of improved efficiency and lower emissions. Although laser ignition shows promise as a durable high-energy ignition system for future high efficiency internal combustion engines, it currently suffers from issues such as large size, high cost, and low efficiency. The development of a miniaturized low cost laser ignition system could enable advancement in the development and commercialization of higher efficiency lower emission engines.

The present study focuses on the ignition and operation of a single cylinder research engine with a diode side pumped passively Q-switched laser and a commercial laser system. The design, construction, and operation of the miniaturized laser system was drawn from prior research [1,2]. The engine operation and emissions data produced by each ignition system was compared and analyzed. 


\section{Background}

The shift to higher compression and leaner fueling conditions has a significant effect on the efficiency and the emissions of an internal combustion engine. Increasing the in-cylinder pressure at the time of ignition produces an increase in the engine efficiency by increasing the power per unit combustion chamber area, which increases the specific power/heat loss ratio. Higher thermal efficiency can also be realized due to higher compression efficiency [3-5]. Subsequent efficiency gains are realized due to a reduction of the pumping losses that result from the higher intake pressures [6,7]. This increased operating pressure acts to offset the loss of power density due to lean operation [5]. The leaner mixture also produces a higher thermal efficiency due to lower heat losses and thermodynamic modification of the fuel/air mixture [3-6]. The increase in efficiency occurs because the excess air increases the ratio of specific heats of the burned gases which increases the work output of the engine during the expansion stroke [6]. The leaner fuel/air mixture produces cooler combustion which dramatically reduces the amount of thermal $\mathrm{NO}_{\mathrm{x}}$ generated by the engine [3-5,8-10].

Prior Laser spark ignition engine testing has shown an extension of the lean limit of operation [3$5,10-15]$ as well as significant reduction of $\mathrm{NO}_{\mathrm{x}}$ emissions $[4,15]$ and reduction of ignition delay $[3,5,16,17]$. Longer burn duration $[3,5,16]$, increased combustion stability $[3,5,15]$, improved performance $[3,5,11,15]$, and laser spark ignition location insensitivity $[11,16]$ are also reported in the literature.

\section{Engine Test Cell}

The test cell used for experimentation in this work is located at the U.S. Department of Energy's National Energy Technology Laboratory facility in Morgantown, West Virginia. The test cell consists of a Ricardo Proteus single cylinder research engine, dynamometer, and control and instrumentation hardware for measuring and/or modifying many of the operational aspects of the engine [18].

The cell is outfitted with a $75 \mathrm{~kW}$ dynamometer which was used to motor the engine for starting before fuel or spark energy was added to the system for full operation. The dynamometer was used to regulate the operational speed of the engine under fueled conditions. The cell includes fuel flow monitors for natural gas and is equipped with temperature controls for the engine coolant, oil, intake air, and the test cell. These controls are vital to the consistency of any tests that are spread over the course of days, weeks or months because they allow for the most similar test situations independent of daily or operational differences. Figure 1 shows a basic schematic of the engine test cell. 


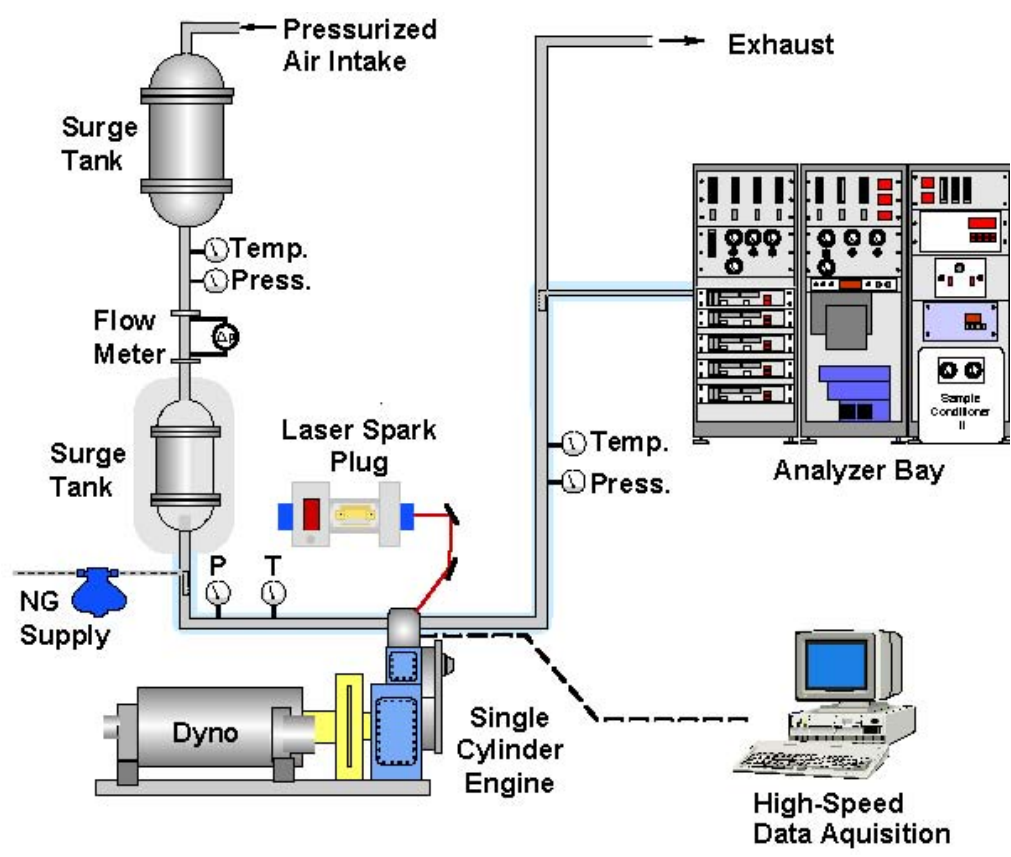

Figure 1: Engine test facility schematic

\section{Engine Test Experimental Setup}

The goal of the engine testing was to compare the engine performance when ignited by the test laser and the commercial laser. The commercial laser system was used in a number of previous research efforts that showed improvements in engine operation and emissions production [1-6]. If the engine testing results for the two laser systems are found to be similar then the assumption can be made that the laser systems will operate similarly at higher repetition rates. The optical arrangements as well as the operational procedures for the ignition testing were similar. The optical arrangement for the commercial laser is shown in Figure 2.

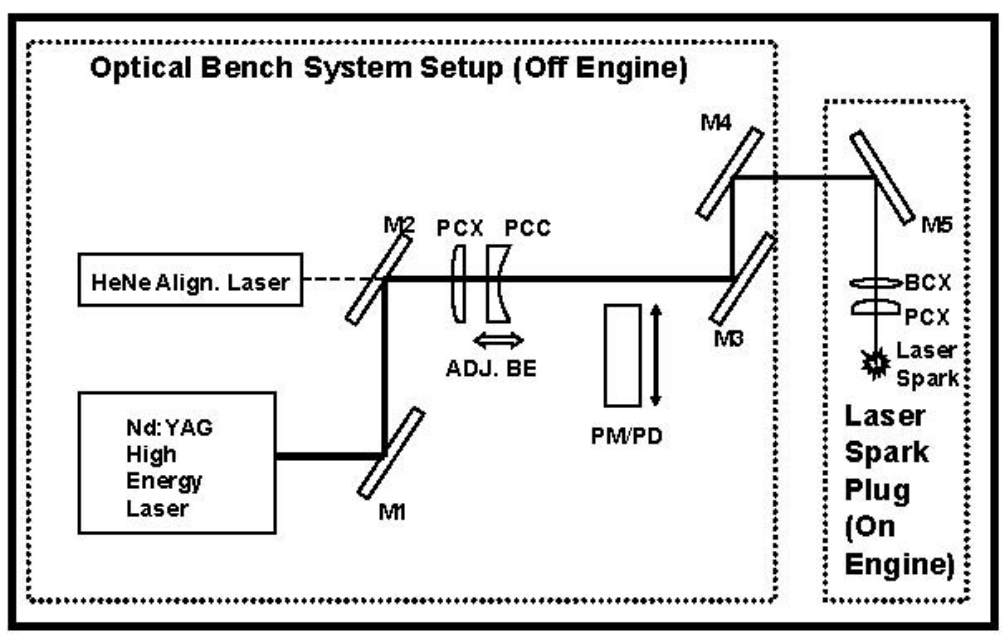

Figure 2: Commercial laser optical setup 
The commercial laser used was a New Wave Research Tempest-20 flashlamp pumped actively Q-switched laser system. The output of the commercial laser was reflected off of two mirrors, M1 and M2, so that the output was made coaxial with a Helium-Neon alignment laser. The laser output was then directed through a two element beam expander that consisted of a fixed planoconvex (PCX) lens with a focal length of $100 \mathrm{~mm}$ and a movable plano-concave (PCC) lens with a focal length of $-50 \mathrm{~mm}$. The output of the beam expander was then directed through a set of two steering mirrors that pointed the laser output from the optics table to the on-engine optics. A movable power meter (PM) and photodiode (PD) setup was employed between the beam expander and the steering mirrors to monitor the laser output characteristics. Once the laser output reached the on-engine optics a single turning mirror, M5, directs the energy through a sapphire lens that also acted as a pressure barrier, for focusing the laser output into the combustion chamber.

The test laser (TL) was able to make use of a less complicated optical setup due to the optical access through the laser cavity. The alignment laser (AL) was directed through the high reflector of the test laser and continued on through the output coupler. This arrangement was used to align the laser as well as align the optical path to the engine. This setup is shown in Figure 3.

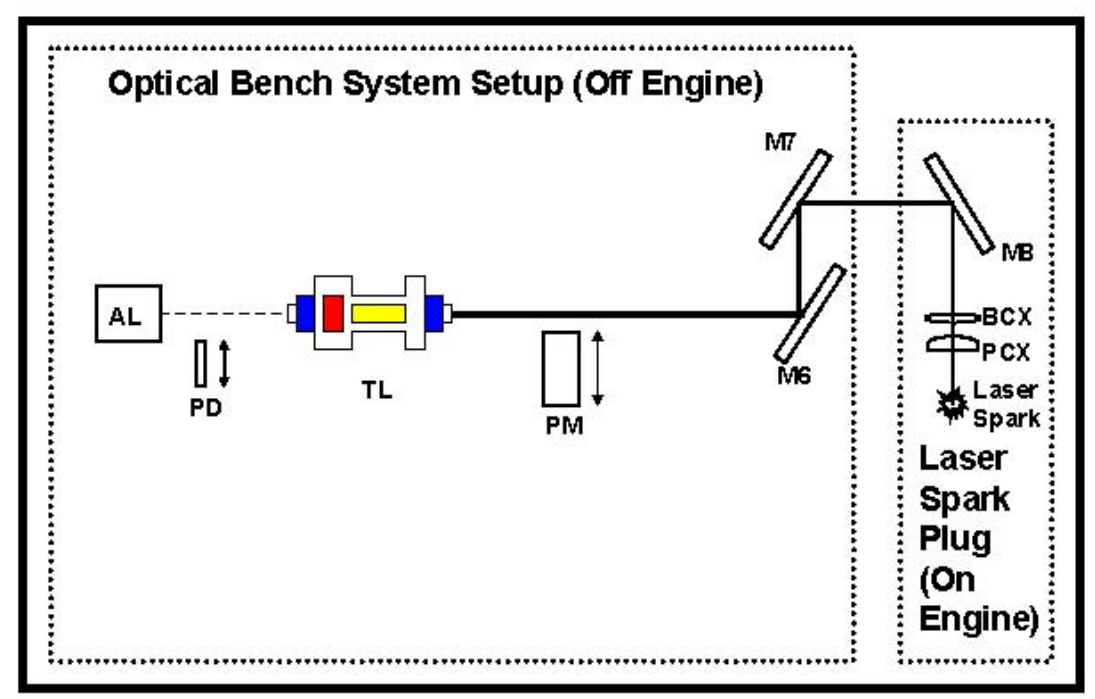

Figure 3: Test laser optical setup

The output pulse width was monitored by a photodiode placed behind the high reflector. The output pulse energy was measured between the laser and the steering optics before the output is directed to the on-engine optics.

Previous work [3-6,10] used a sapphire window/lens with a focal length of approximately $31 \mathrm{~mm}$ such that the focal spot would produce a spark approximately $6 \mathrm{~mm}$ below the bottom of the head and above the piston crown as shown in Figure 4 (A). This arrangement kept the spark away from the walls of the combustion chamber to reduce quenching effects and enhance the propagation of the flame front evenly across the combustion chamber. 


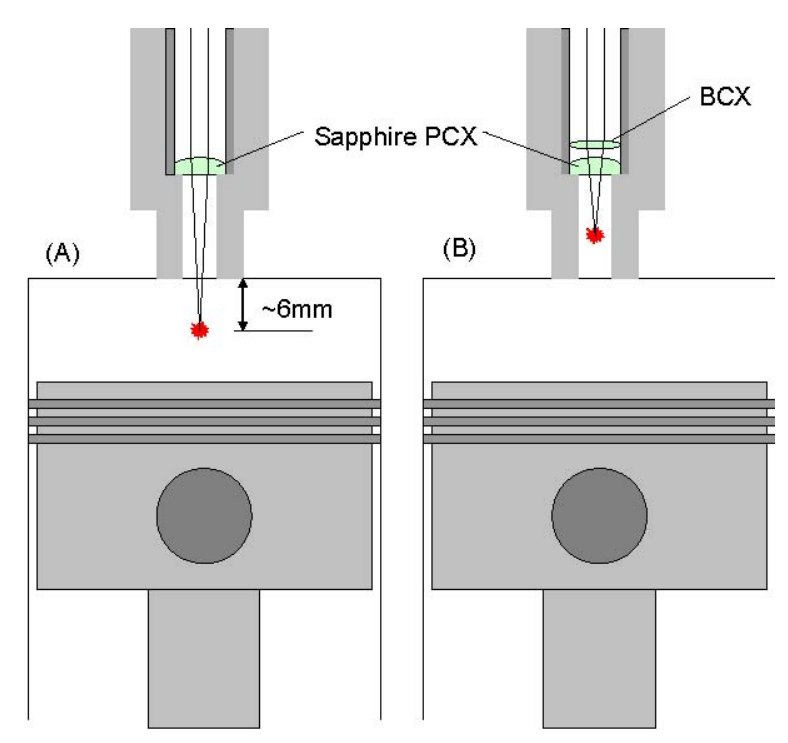

Figure 4: Schematic illustrating the original ignition location (A) and the modified ignition location (B) [Not to scale]

The current setup used an additional lens placed upstream from the sapphire lens to modify the focal length of the assembly as shown in Figure 4 (B). The additional lens was a fused silica biconvex lens with a focal length of approximately $18 \mathrm{~mm}$. The addition of this lens shortened the overall focal length of the setup to approximately $12 \mathrm{~mm}$. This was done to improve the spark performance of the test laser due to multimode output production. Shortening of the focal length provides a smaller focal spot that greatly increases the focal intensity of a given output pulse. This placed the laser spark well inside the optical access cavity shrouding the spark. This arrangement did however allow the multimode output of the test laser to produce consistent sparks for engine testing. This modification was the primary reason for not making an additional engine operational comparison with an electrical ignition system. It was felt that the spark location produced by the modified optics could not be sufficiently reproduced with the available electrical ignition system.

Although the test laser performed well in the optics laboratory and consistently produced sparks under tightly controlled conditions this "good behavior" did not transfer into the engine laboratory. Due to design deficiencies of the test laser it was not able to symmetrically reject the heat built up over prolonged operation at the higher repetition rates encountered during engine testing. The inability to sufficiently shed heat led to minor issues with the alignment of the laser due to thermal expansion of the chassis. Therefore the laser had to be "warmed up" slowly to ensure even heat distribution to maintain proper alignment. In addition to the problem of alignment was the issue of sporadic multimode output.

Under the more harsh conditions seen in the engine test laboratory with higher repetition rates, thermoelectric cooling, engine heat, etc. the laser could not be aligned to consistently produce single mode output pulses. Therefore, the shorter focal length lens arrangement had to be employed to ensure consistent laser spark production. The excess heat produced by operating the laser at higher repetition rates limited operation of the laser system to $5 \mathrm{~Hz}$, or an engine speed of approximately $600 \mathrm{rpm}$. This engine speed is typically an idling condition for large 
power generation reciprocating engines and was sufficient to demonstrate the operation of the test laser and the commercial laser for comparison. A schematic of the laser is shown in Figure 5.

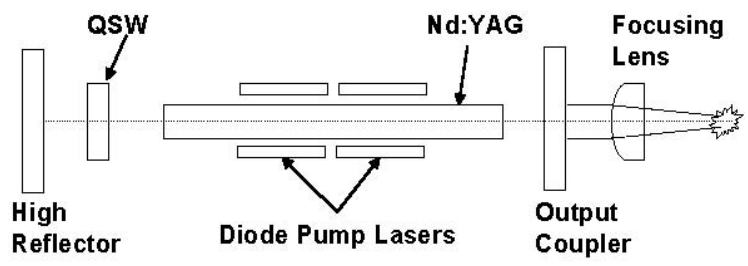

Figure 5: Diode pumped passively Q-switched laser diagram.

The four key test laser design parameters and their values are as follows: Output Coupler Reflectivity - R=30\%, Q-switch Initial Transmission - To=32\%, Neodymium Concentration $\mathrm{Nd}=0.5 \%$, and Laser Diode Optical Output $-\mathrm{P}_{\text {in }}=1007$ Watts. This particular combination of optics was chosen because they produced the highest and most consistent output with the least amount of alignment difficulty. The laser output parameters used in the engine study are listed in Table 1. The commercial laser output energy was selected to match the test laser output pulse energy as closely as possible. When this commercial laser system was operated near the output threshold the output pulse width became much broader than at higher output conditions and deviated significantly from the data sheet specifications. This operational quality of the commercial laser system was not discovered until after the engine testing had been performed and the apparatus disassembled. Accordingly, the primary differences in the values between the test and commercial laser outputs are listed in Table 1. Future testing will alleviate this problem by operating the commercial laser near its maximum and attenuating the signal to match the test laser output more closely.

Table 1: Laser output engine test parameters list

\begin{tabular}{|l|c|c|}
\hline \multicolumn{1}{|c|}{ Parameter } & $\begin{array}{c}\text { Test Laser } \\
\text { (Multi mode } \\
\text { Output) }\end{array}$ & $\begin{array}{c}\text { Commercial } \\
\text { Laser }\end{array}$ \\
\hline Output Energy (mJ) & 16 & 23 \\
\hline Pulsewidth (ns) & 9 & 18 \\
\hline Peak Power (MW) & 1.7 & 1.27 \\
\hline Beam Quality or M ${ }^{2}$ & 6.55 & 6.25 \\
\hline Beam Diameter (mm) & $\sim 3$ & $\sim 3$ \\
\hline Focal Intensity (W/cm ${ }^{2}[31 \mathrm{~mm}$ lens $]$ & $2.8 \times 10^{10}$ & $2.2 \times 10^{10}$ \\
\hline Focal Intensity (W/cm ${ }^{2}[12 \mathrm{~mm}$ lens $]$ & $1.9 \times 10^{11}$ & $1.5 \times 10^{11}$ \\
\hline
\end{tabular}




\section{Characteristic Engine Data}

The engine testing for each laser system was performed on nonconsecutive days. The engine test plan consisted of three replications of three equivalence ratios randomized for each laser ignition system. All other independent variables remained constant. Preliminary engine operation with the test laser allowed for the determination of an acceptable range of values for the equivalence ratio $(\Phi)$ that would not cause misfire.

The coefficient of variation (COV) of the IMEP is used as an indication of how smooth or rough the combustion is over a period of time. Lower COV values indicate less variation in the incylinder pressure data and hence smoother combustion. Once the COV of IMEP value exceeds $10 \%$ [3] the engine is considered to be misfiring. The COV of IMEP for both the test laser, 1.14$2.84 \%$, and the commercial laser, $1.18-2.87 \%$, are relatively low indicating smooth combustion. The IMEP COV values are approximately equal indicating a high degree of similarity in the combustion conditions produced by the two ignition systems.

In-cylinder pressure and heat release rate data were recorded so that the combustion characteristics produced by each ignition system could be analyzed and compared. Figures 6-10 show representative pressure traces and calculated heat release rates (HRR) as a function of crank angle degrees. Figure 6 shows the pressure curves and HRR waveforms produced by the test laser at three different equivalence ratios. An increase in $\Phi$ advances the HRR as well as the peak pressure. The extremely long ignition delay was characteristic of the ignition systems due to the shortened focal length and subsequent shrouding of the spark kernel. Shrouding the ignition spark, as described in the previous section, restricts the expansion of the flame front. Top dead center (TDC) is reached before the initial flame kernel has expanded sufficiently to induce ignition at or near TDC.

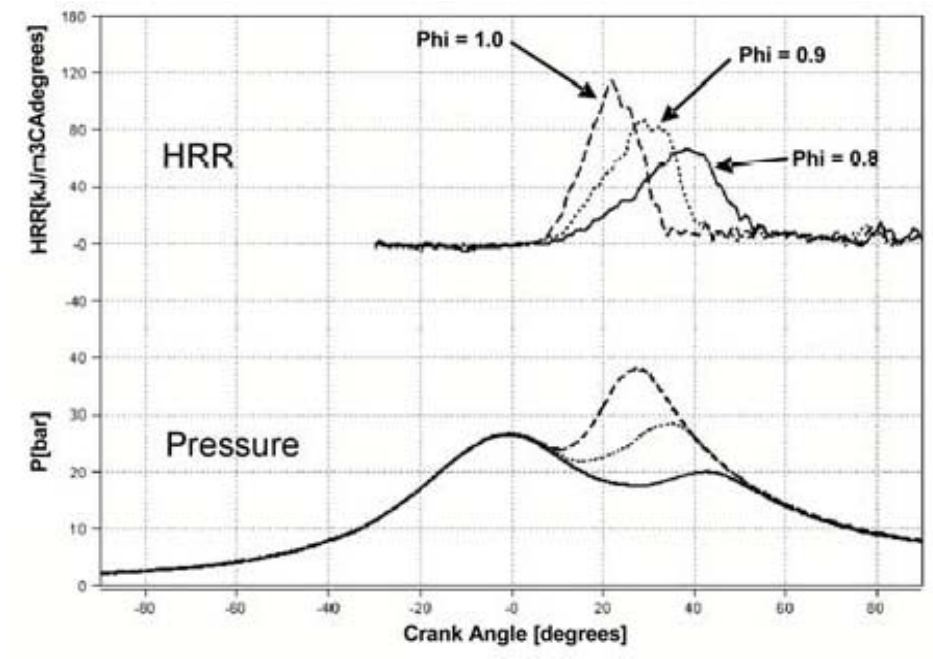

Figure 6: Test laser pressure and heat release rate waveforms for varying phi. Solid line $\Phi=0.8$, Dotted line $\Phi=0.9$, Dashed line $\Phi=1.0$

Figure 7 shows the pressure curves and HRR waveforms produced by the commercial laser system at three different equivalence ratios. A comparison between Figures 6 and 7 shows that the in-cylinder data produced by both the test laser and the commercial laser are virtually 
identical. This comparison is also shown in Figures 8-10 where the pressure curves and HRR traces for both lasers are compared for each equivalence ratio.

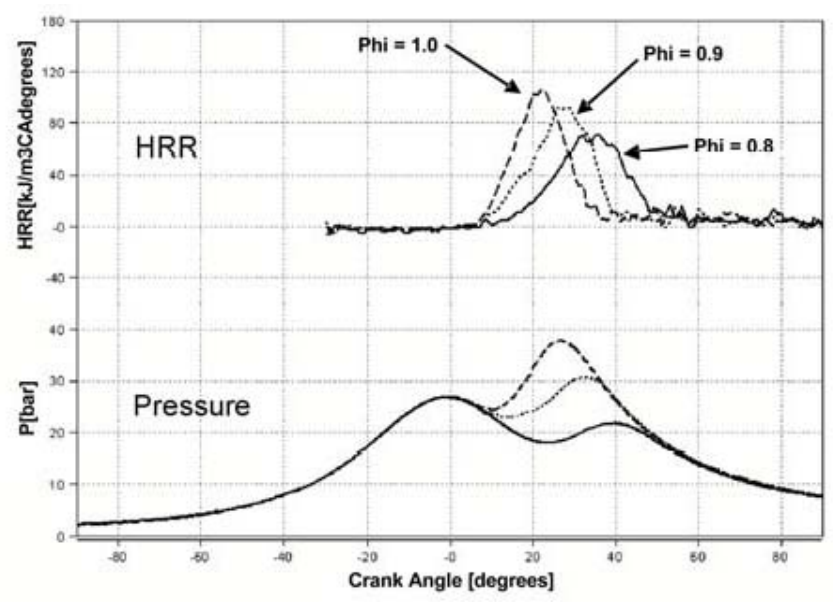

Figure 7: Commercial laser pressure and heat release rate waveforms for varying phi. Solid line $\Phi=0.8$, Dotted line $\Phi=0.9$, Dashed line $\Phi=1.0$

Figure 8 shows the data for each laser system for an equivalence ratio of $\Phi=0.8$. Figure 9 shows the data for each laser system for an equivalence ratio of $\Phi=0.9$. Figure 10 shows the data for each laser system for an equivalence ratio of $\Phi=1.0$. For each equivalence ratio it can be seen that the ignition delay, peak pressure and heat release waveforms are all virtually identical.

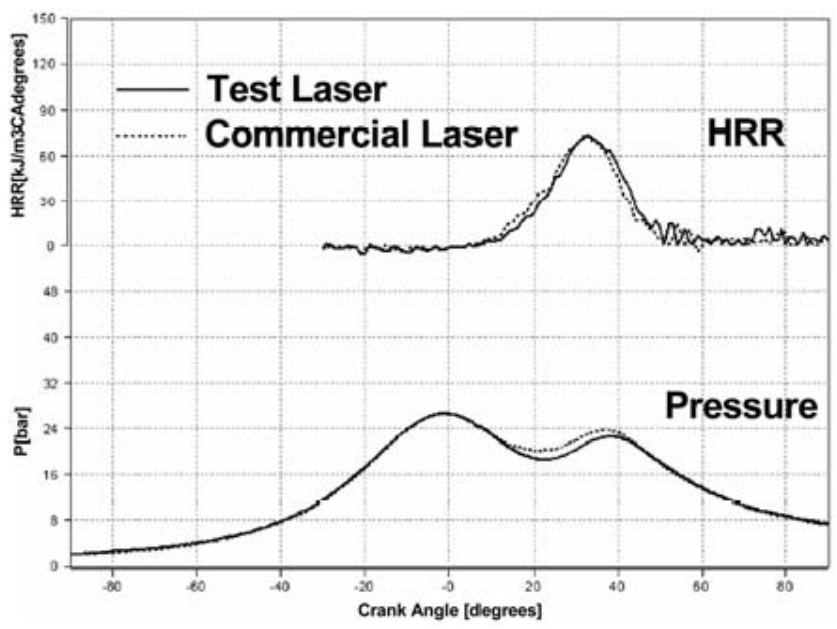

Figure 8: Comparison of pressure and heat release rate waveforms for $\Phi=0.8$ 


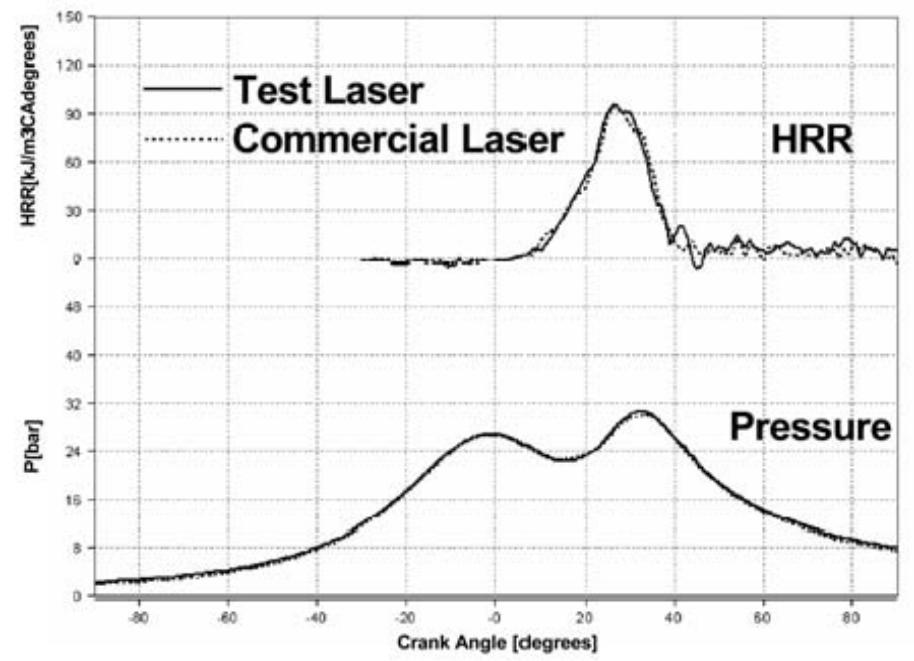

Figure 9: Comparison of pressure and heat release rate waveforms for $\Phi=0.9$

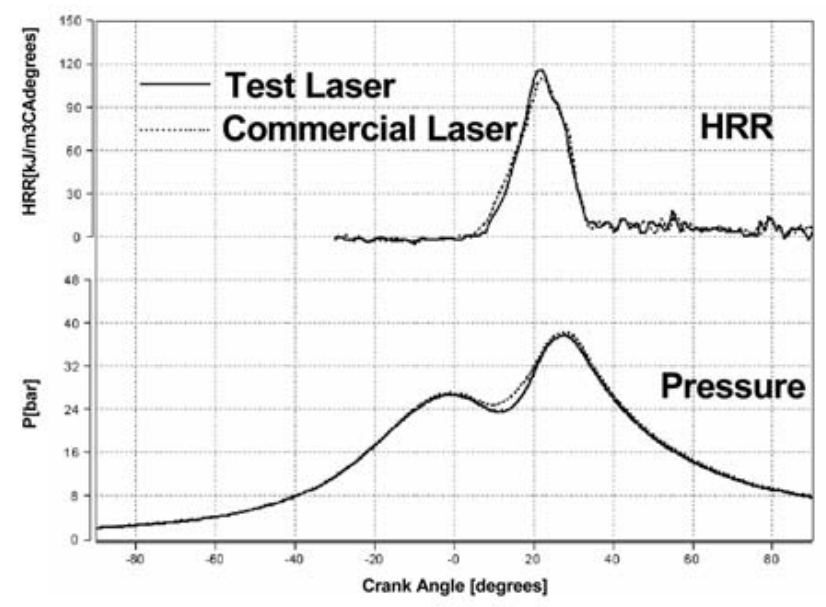

Figure 10: Comparison of pressure and heat release rate waveforms for $\Phi=1.0$

Figure 11 shows the ignition delay produced by each laser system for each equivalence ratio. The ignition delay data simply confirms the trends in the pressure and HRR data shown in Figures 6 and 7. The ignition delay decreases as the equivalence ratio is increased toward stoichiometry. The data for each laser system is statistically identical for the cases where $\Phi=0.8$ and $\Phi=0.9$. Overall there is little difference in the ignition delay produced by each laser system. 


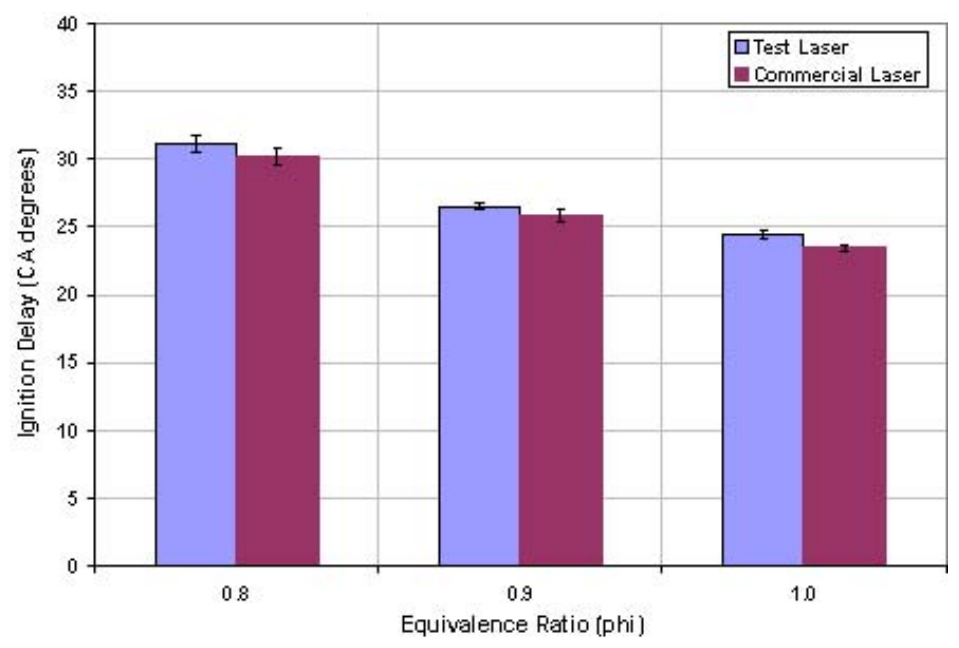

Figure 11: Ignition delay comparison between the test laser and the commercial laser for varying $P$ hi

\section{Engine Emissions Data}

Engine emissions data was taken to determine differences between the exhaust emissions concentrations from the operation of each laser system. Figures 12-14 show the measured $\mathrm{NO}_{\mathrm{x}}$, $\mathrm{CO}$, and total hydrocarbon (THC) emissions, respectively, with respect to equivalence ratio. Figure 12 illustrates the $\mathrm{NO}_{\mathrm{x}}$ emissions for both ignition systems at each equivalence ratio. The data shows a significant decrease in the $\mathrm{NO}_{\mathrm{x}}$ emissions as the equivalence ratio is decreased. $\mathrm{NO}_{\mathrm{x}}$ production is highly temperature dependent and as the equivalence ratio is lowered the combustion temperature decreases. This reduction in combustion temperature significantly lowers the $\mathrm{NO}_{\mathrm{x}}$ production. The changes in load as well as the dilution of the charge are contributors to the differences in the $\mathrm{NO}_{\mathrm{x}}$ emissions. $\mathrm{NO}_{\mathrm{x}}$ emissions data were normalized to the equivalence ratio to account for differences in the raw exhaust due to the variations in fueling to vary the equivalence ratio. All emission data were normalized to its respective equivalence ratio value. The data error bars depict a single standard deviation. $\mathrm{NO}_{\mathrm{x}}$ emissions from the test laser and the commercial laser results are statistically identical.

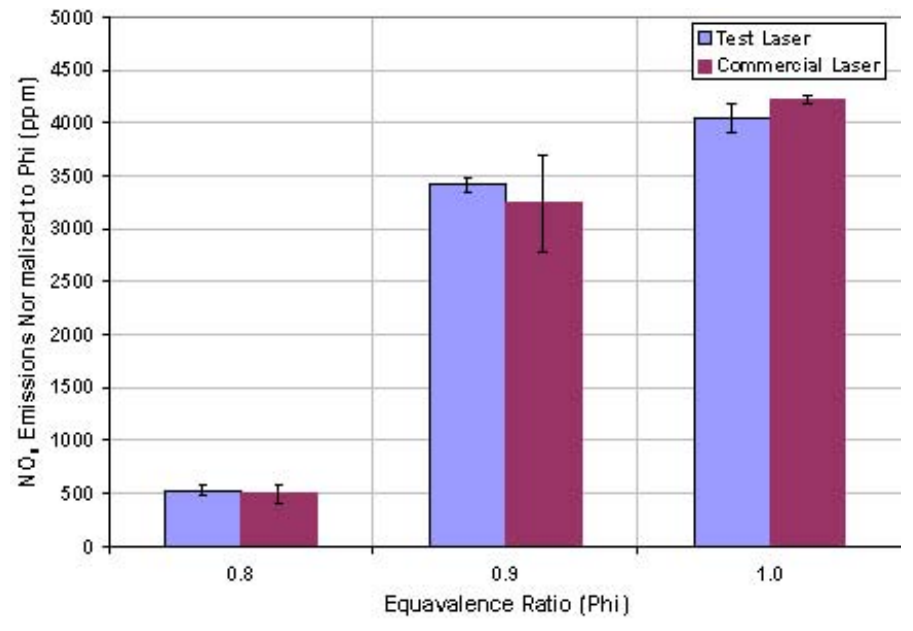

Figure 12: Comparison of $\mathrm{NO}_{\mathrm{x}}$ emissions normalized to Phi 
Figure 13 illustrates the $\mathrm{CO}$ emissions for both ignition systems at each equivalence ratio. The data show a steady increase in the $\mathrm{CO}$ emission as the equivalence ratio was decreased. This increase in $\mathrm{CO}$ is primarily due to incomplete combustion most likely due to the large ignition delay produced by the shorter focal length. In addition, the flame front does not see the higher pressures that occur near TDC due to the ignition delay. This is indicated by the decrease in CO emissions as the equivalence ratio is increased to stoichiometric conditions thereby advancing the timing and shortening the ignition delay as seen in the previous section. The change in load could also be a contributor to the difference in the $\mathrm{CO}$ emissions. Overall the test laser and commercial laser performed relatively the same except when $\Phi=0.8$. At this operating point the commercial laser ignition system produced a consistently larger amount of $\mathrm{CO}$.

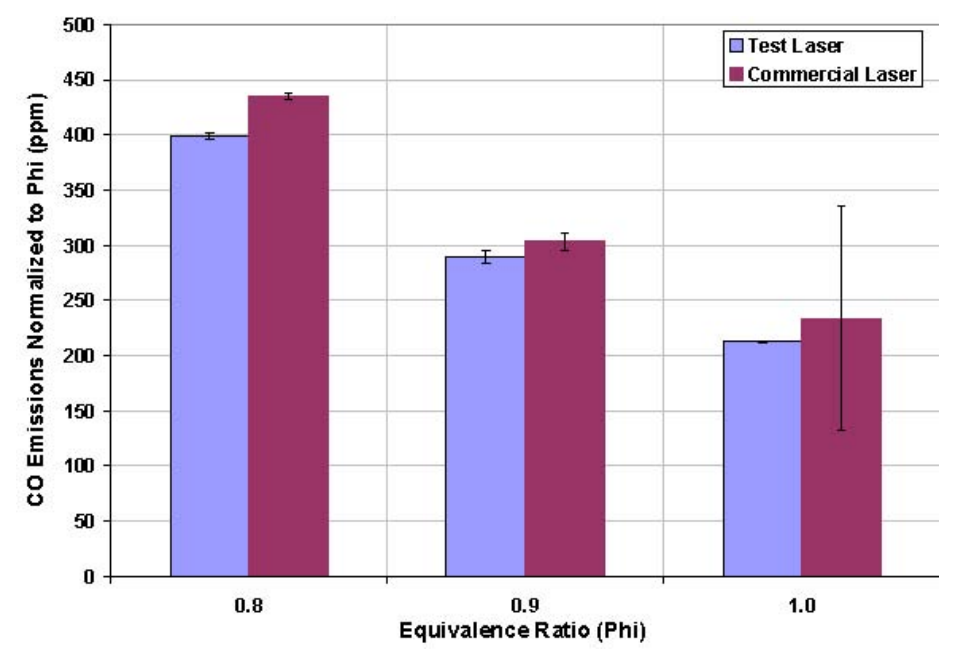

Figure 13: Comparison of CO emissions normalized to Phi

Figure 14 shows the total hydrocarbon (THC) emissions for both ignition systems at each equivalence ratio. There are no noticeable trends in the THC data because overall the combustion was poor at all equivalence ratios. The poor combustion was primarily due to the shrouded spark and the ignition delay that it produced. The ignition delay meant that the bulk of the combustion happened on the down stroke of the piston and not at the top of the stroke where more rapid chemical heat release is expected and where the greatest amount of power is developed by the system. The ignition delay allowed for a significant amount of unburned fuel to be passed into the exhaust because of the poor and incomplete combustion that it fostered. The data indicates that the THC emissions are statistically identical between the two laser systems and relatively constant and similar with changing equivalence ratio. The consistency of the THC emission data could possibly be due to the fact that the combustion was poor and incomplete in each case. However the more incomplete combustion at the lower equivalence ratio values contributed more $\mathrm{HC}$ emissions which happened to be similar to the emissions produced by the higher equivalence ratio values with more complete combustion. This is evidenced in the heat release rate data discussed earlier in this chapter. The data acquired during engine testing cannot be compared to the previous laser ignition work performed at NETL $[3-6,10]$ due to the vastly different operating conditions. The previous commercial laser ignition research was conducted at a higher engine speed with lower equivalence ratio values with a boosted intake pressure. 


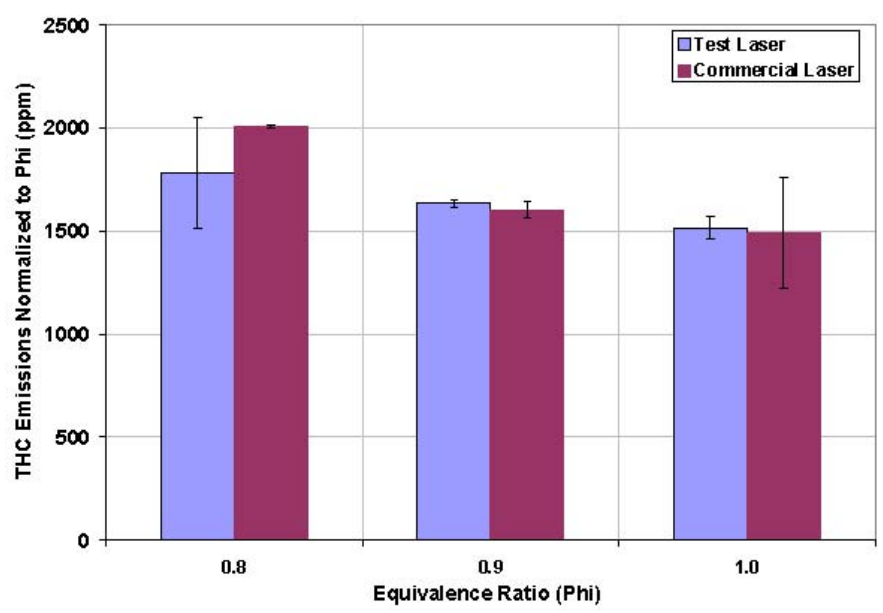

Figure 14: Comparison of total hydrocarbon emissions normalized to Ph

\section{Conclusions}

The goal of the engine testing was to show that the test laser performs identically to the commercially available flashlamp pumped actively Q-switched laser used in previous laser ignition testing. The engine testing consisted of a comparison of the in-cylinder, and emissions behavior of the engine using each of the lasers as an ignition system. All engine parameters were kept as constant as possilbe while the equivalence ratio was varied between $0.8,0.9$, and 1.0 . The test laser was constructed with a $30 \%$ output coupler, 32\% Q-switch initial transmission, and a $0.5 \% \mathrm{Nd}$ concentration rod all pumped by 1007 Watts of optical power. The test laser multi mode output pulse energy was approximately $16 \mathrm{~mJ}$, with a pulsewidth of $9 \mathrm{~ns}$, and an $\mathrm{M}^{2}$ of 6.55. This output produced focal intensity of approximately $190 \mathrm{GW} / \mathrm{cm}^{2}$ with the $12 \mathrm{~mm}$ modified on-engine optical arrangement. The commercial laser had similar output parameters and both laser systems operated the engine with similar results. Due to the shortening of the focal length of the on-engine optical setup both laser systems produced a spark well within the optical transfer cavity. This shrouded spark led to a very long ignition delay and retarded combustion timing for all three equivalence ratios. This was evidenced by the in-cylinder pressure traces and the HRR waveforms. The emissions data indicate that both lasers produced very similar combustion. The ignition delay caused by the shrouded spark delayed the combustion until after TDC, which led to poor combustion that produced high levels of CO and THC.

The current test laser design suffered from a number of curable issues including heat and vibration sensitivity, and repetition rate limitations. Future work includes the development of an optical engine adaptor that uses a shorter focal length lens that is situated closer to the combustion chamber. The test laser was primarily used to investigate the range of optical parameter combinations that produce laser sparks. The knowledge gained from the current test laser design is being used to develop an end pumped laser that is smaller, more powerful, virtually insensitive to heat and vibrations, and remotely pumped by a fiber optic coupled laser diode bank. The second phase laser prototype will be mounted directly to the engine in a coilover-plug arrangement. 


\section{Acknowledgements}

The authors would like to thank the United States Department of Energy's National Energy Technology Laboratory (NETL) and the Advanced Reciprocating Engine Systems (ARES) Program. We would also like to thank reciprocating engine program team leader John Ontko, Contract support personnel Doug Horton and Todd Worstell, and Graduate students Sam George and Jacinto Solano.

\section{References}

1. McIntyre, D.L., “A Laser Spark Plug Ignition System for a Stationary Lean-Burn Natural Gas Reciprocating Engine,” Dissertation, West Virginia University, 2007.

2. McIntyre, D.L., Woodruff, S.D., McMillian, M.H., Richardson, S.W., Gautam, M., "Laser spark plug development," SAE Paper 2007-01-1600, 2007.

3. McMillian, M.H., Richardson, S., Woodruff, S.D., and McIntyre, D., "Laser-Spark Ignition Testing in a Natural Gas-Fueled Single-Cylinder Engine," SAE Paper 2004-01-0980, March 2004.

4. Richardson, S., McMillian, M.H., Woodruff, S.D., McIntyre, D.L., "Misfire, Knock and NOx Mapping of a Laser Spark Ignited Single Cylinder Lean Burn Natural Gas Engine," SAE paper 2004-01-1853, June 2004.

5. McMillian, M.H., Woodruff, S.D., Richardson, S.W., McIntyre, D.L., "Laser Spark Ignition: Laser Development and Engine Testing," Paper Number ICEF2004-917, Proceedings of ICEF04 2004 Fall Technical Conference of the ASME Internal Combustion Engine Division, October 24-27, 2004, Long Beach, California, USA.

6. Richardson, S.W., McMillian, M.H., Woodruff, S.D., Worstell, T., McIntyre, D.L., "Laser Spark Ignition of a Blended Hydrogen-Natural Gas Fueled Single Cylinder Engine," Proceedings of ASME ICE Division, ICES2006-1397, Spring Technical Conference, May 2006, Aachen, Germany.

7. Ivanic, Z., Ayala, F., Goldwitz, J.A., Heywood, J.B., "Effects of Hydrogen Enhancement on Efficiency and NOx Emissions of Lean and EGR-Diluted Mixtures in a SI Engine," SAE Paper 2005-01-0253.

8. Aherns, D.L., Yalin, A.P., Olsen, D.B., Kim, G.H., "Development of an Open Path Laser Ignition System for a Large Bore Natural Gas Engine: Part 1 System Design," Paper Number ICEF2005-1060, Proceedings of ASME Internal Combustion Engine Division 2005 Spring Technical Conference, April 5-7, 2005, Chicago, Illinois, USA.

9. Dale, J.D., Smy, P.R., Clements, R.M., "Laser Ignited Internal Combustion Engine - An Experimental Study," SAE Paper 780329, 1978.

10. McMillian, M.H., Woodruff, S.D., Ontko, J.S., Richardson, S.W., McIntyre, D.L., "LaserSpark Ignition for Natural Gas Fueled Reciprocating Engines," Natural Gas Technologies Conference and Exposition, Orlando, Florida, Sept. 29 - Oct. 2, 2002. 
11. Dale, J.D., Smy, P.R., Clements, R.M., "Laser Ignited Internal Combustion Engine - An Experimental Study,” SAE Paper 780329, 1978.

12. Alger, T., Mehta, D., Chadwell, C., Roberts, C., "Laser Ignition in a Pre-Mixed Engine: The Effect of Focal Volume and Energy Density on Stability and the Lean Operating Limit," SAE Paper 2005-01-3752, 2005.

13. Bihari, B., Gupta, S.B., Sekar, R.R., Gingrich, J., Smith, J., "Development of Advanced Laser Ignition System for Stationary Natural Gas Reciprocating Engines," Proceedings of ASME ICE Division, ICEF2005-1325, 2005 Fall Technical Conference, September 11-14, Ottawa, Canada.

14. Kopecek, H., Charareh, S., Lackner, M., Forsich, C., Winter, F., Klausner, J., Herdin, G., Weinrotter, M., Wintner, E., "Laser Ignition of Methane-Air Mixtures at High Pressures and Diagnostics," Journal of Engineering for Gas Turbines and Power, Jan. 2005, Vol. 127, pp. 213219.

15. Herdin, G., Klausner, J., Wintner, E., Weinrotter, M., Graf, J., "Laser Ignition a New Concept to Use and Increase the Potentials of the Gas Engines," ICEF2005-1352, ASME Internal Combustion Engine Division 2005 Fall Technical Conference, September 2005, Ottawa, ON Canada.

16. Smith, J.R., "Comparison of Ignition Locations in a High Swirl Engine," Sandia Labs. SAND-79 -8715, (1979).

17. Ahrens, D.L., Olsen, D.B., Yalin, A.P., "Development of an Open Path Laser Ignition System for a Large Bore Natural Gas Engine: Part 2 Single Cylinder Demonstration," Proceedings of ASME ICE Division, ICES2005-1317, 2005 Fall Technical Conference, September 11-14, Ottawa, Canada.

18. Proteus Single Cylinder Research Engine No. 102 Instruction and Operating Manual, 1986.

\section{Contact Information}

Dustin L. McIntyre, PhD

3610 Collins Ferry Road, MS: N05

Morgantown, WV 26507

dustin.mcintyre@netl.doe.gov

(304)-285-1374 ph

(304)-285-4469 fax 